\title{
Lepra e investigación bacteriológica en Colombia: los casos de Carrasquilla y de Lleras
}

\author{
Diana Obregón \\ Profesora Asociada, Departamento de Historia, Facultad de Ciencias Humanas, \\ Universidad Nacional de Colombia, Bogotá, D.C., Colombia.
}

La lepra ha ocupado un lugar especial en la historia de Colombia. Introducida supuestamente por los conquistadores españoles, fue objeto de atención por parte de los gobiernos tanto coloniales como republicanos y, con frecuencia, confundida con la sífilis y con otras enfermedades. Desde finales del siglo XIX, los médicos colombianos trataron la lepra como un grave problema de higiene pública, y lograron transmitir ese sentimiento de urgencia al gobierno y al resto de la población (12).

La tesis que desarrollo en este trabajo es que la lepra fue uno de los vehículos de institucionalización de la investigación biomédica en Colombia. No fue el único, pero quizás si uno de los más importantes. Restringiré mi exposición a los investigadores Juan de Dios Carrasquilla y Federico Lleras Acosta, quienes probablemente asumieron más cabalmente que cualquiera otro en su tiempo en Colombia, el programa científico de la bacteriología.

En una larga polémica contra la teoría de la lepra como una enfermedad hereditaria, Carrasquilla señalaba en 1889, citando a Koch: "Las enfermedades infecciosas no provienen, como se creía antes, de cuerpos fluidos, es decir, gaseosos, de miasmas, sino de cuerpos sólidos, de polvos... Las enfermedades infecciosas no son jamás producidas por el desaseo, por la viciación del aire que proviene de la aglomeración de hombres, por el hambre, la pobreza, las privaciones, ni por la suma de todos estos factores, que es lo que se ha llamado miseria social, ni por las influencias

Correspondencia:

Calle 65 No. 50-01, apartamento 605

Recibido: 12/05/00; aceptado: 26/05/00 climatéricas. Sus gérmenes específicos son los únicos que pueden producirlos" (sic) (3).

Carrasquilla continuaba explicando que así como una enfermedad no aparece si no existe el microorganismo especial que la produce, una enfermedad tampoco se transforma en otra, ni un microbio engendra otro de distinta especie. Tampoco las enfermedades de los padres se pueden transmitir a los hijos por vía de generación, ellas sólo se transmiten por contagio o por infección. Estas afirmaciones eran importantes por cuanto desde tiempos medievales se había creido que la lepra era el último estadio de la sífilis y se la había confundido con muchas otras dolencias. Por lo demás, médicos tan importantes en el estudio de la lepra como los noruegos Daniel Danielssen y Carl W. Boeck, quienes habian realizado su descripción anatomo-patológica en 1847, la tenían por hereditaria (4).

La convicción de la certeza del método bacteriológico llevó a Carrasquilla a buscar posibilidades terapéuticas para la lepra. De esta manera nació la seroterapia Carrasquilla. La seroterapia se basaba en un principio explicado por el alemán Emil von Behring y por el japonés Shibasaburo Kitasato en 1890. Estos científicos inocularon conejos y ratones con cultivos de tétanos y encontraron que su inmunidad dependía de la capacidad del suero de neutralizar las toxinas producidas por el bacilo del tétano. Esta capacidad era durable y, además, podía ser transferida a otros animales. El éxito de las antitoxinas contra el tétano y luego contra la difteria, en la época dorada de la bacteriología, hizo pensar que la seroterapia era la panacea contra las enfermedades infecciosas, hasta el primer accidente fatal ocurrido 
en 1896. Como medida preventiva, el médico alemán Langerhans inoculó antitoxinas a su hijo en perfecta salud, causándole la muerte. Además, los científicos pronto encontraron que en muchos casos no había diferencia entre el suero inmune y el normal; ambos podían eventualmente conferir inmunidad. En consecuencia, el suero no parecía ser un tratamiento específico y la seroterapia fue abandonada (5).

El patólogo vienés Victor Babes había intentado la seroterapia inoculando enfermos de lepra con suero de perros que habían sido inmunizados contra la tuberculosis; este suero producía un efecto tónico en los pacientes. Carrasquilla, en cambio, preparaba el suero directamente de la sangre de los pacientes de lepra usando caballos; su método se inspiraba en la analogía entre la lepra y la sífilis. El gobierno colombiano, entonces, creó el Instituto Seroterapéutico para proseguir estas investigaciones. A pesar de los deseos de Carrasquilla y de la retórica oficial que lo presentaba como 'el salvador' de los leprosos, los resultados eran diversos: algunos pacientes mejoraban, mientras que en otros los síntomas se agravaban. Estos experimentos tuvieron amplia difusión: por ejemplo, en la Real Academia de Medicina de Madrid se informó sobre el 'método Carrasquilla' en 1896.

En 1897, Carrasquilla asistió como delegado de Colombia al Congreso Internacional de la Lepra de Berlín donde la seroterapia fue uno de los temas de discusión (6). Este congreso puso de presente que el suero Carrasquilla había sido puesto a prueba por los investigadores alemanes Edward Arning y Albert Neisser y por médicos de Argelia, Londres y Copenhage; también había sido usado en el Hospital de Saint Louis de París, en la Escuela Hematológica de Viena y en el hospital para leprosos de Robben Island en Suráfrica. Sin embargo, el juicio del congreso de Berlín no fue favorable para Carrasquilla; la Academia Colombiana de Medicina conceptuó que el método era inocuo y, aunque lo estimulaba a continuar sus investigaciones, el gobierno le retiró su apoyo. El Instituto Seroterapéutico decayó y con él murió el sueño de Carrasquilla de convertir este centro de investigación en un Instituto Pasteur en Colombia, al estilo de los que existían en Túnez,
Saigón o Marruecos. Ahora bien, en un momento determinado de este proceso, se presentó una polémica con otro médico colombiano, Carlos Putnam, quien había iniciado la aplicación de la seroterapia en el lazareto de Agua de Dios. Carrasquilla protestó ante la Academia de Medicina porque consideró que se le estaban usurpando sus derechos de prioridad por el invento del método. Putnam tuvo que suspender sus experimentos con los leprosos y la Academia dictaminó que la prioridad de la invención de la seroterapia correspondía a Carrasquilla (7).

El caso de Carrasquilla puso en evidencia el nuevo papel social y científico de la profesión médica. Putnam tuvo que suspender sus experimentos en Agua de Dios mientras el asunto de la seroterapia se definía en otra instancia: la Academia de Medicina. Hasta entonces, debido a que la práctica médica estaba escasamente regulada, el éxito o el fracaso de los tratamientos empíricos ofrecidos por médicos o por curanderos permanecía como un asunto privado. Con la profesionalización de la medicina, las cuestiones relativas a la terapéutica pasaron a ser del dominio de un cuerpo profesional que poseía el poder de aprobar o de rechazar una determinada práctica. En segundo lugar, el análisis de la historia de la seroterapia Carrasquilla muestra que la investigacion científica comenzaba a tener importancia en Colombia: los médicos empezaban a derivar su prestigio profesional de este tipo de estudios, más que de una relación privada con una clientela.

En cuanto a la lepra, Carrasquilla, a diferencia de la mayoría de sus colegas, se opuso a considerarla como una enfermedad especial. En el trabajo que presentó en 1897 en el Congreso de Berlín, Carrasquilla criticó las propuestas que conducían a tratar a los enfermos de lepra como si fuesen criminales. Se refería a estos procedimientos como políticas de exterminación basadas en la falsa creencia de que la lepra era altamente contagiosa. Carrasquilla impugnaba la afirmación de que el aislamiento era el único método para detener la expansión de la lepra. Si las políticas de segregación tuviesen bases científicas, afirmaba, habría que aplicar los mismos métodos a todas las enfermedades infecciosas incluyendo la tuberculosis y la sífilis (8). 
Hacia 1905, cuando se celebró el Tercer Congreso Científico Latinoamericano en Río de Janeiro, Carrasquilla había modificado su posición de dieciseis años antes sobre la miseria y las enfermedades infecciosas. En aquel congreso discutió sobre la etiología y la profilaxis de la lepra, afirmando que, antes que por condiciones climáticas o telúricas, la propagación de la lepra se producía por circunstancias sociales, tales como la pobreza; que las decisiones del gobierno colombiano se traducían simplemente en persecusión al enfermo; que la lepra era una enfermedad de evolución lenta, apenas ligeramente contagiosa y que las ideas generalizadas sobre la transmisión de la lepra a través del uso de objetos manipulados por los pacientes o a través de relaciones sexuales, idea de origen medieval, eran sólo fábulas. Aunque Carrasquilla creía en medidas tales como prohibir la inmigración de pacientes de lepra y aceptaba el aislamiento, se opuso a la segregación de los enfermos en colonias remotas. Ante todo, este médico abogaba por la creación de hospitales donde la lepra fuese tratada como cualquier otra enfermedad: "...el aislamiento por sí solo, el aislamiento empírico, que no tiene por objeto sino librarse de los enfermos, no tiene razón de ser; ... es inhumano, carece de eficacia y debe reemplazarse por otros medios de profilaxis racionales" (9).

Para Carrasquilla, los hospitales debían estar localizados en los municipios donde médicos, asistentes y medicamentos estuvieran disponibles. En el plan de Carrasquilla, el propósito de los hospitales para los pacientes de lepra era buscar su cura a través de la higiene, estudiar la enfermedad e investigar sobre tratamientos científicos como se había hecho en Noruega (10). Carrasquilla sugirió adoptar el modelo de los sanatorios para la tuberculosis, cuyo tratamiento higiénico y racional se puso de moda en Europa y en los Estados Unidos a principios del siglo XX. Sin embargo, pocos de sus colegas compartían ese enfoque, y quienes, como Federico Lleras Acosta, se interesaron por continuar las investigaciones bacteriológicas iniciadas por él, reforzarían un punto de vista estrechamente reduccionista.
La bacteriología, como he insinuado, fue un poderoso vehículo de difusión de la ideología de la ciencia. Aunque los médicos colombianos estaban familiarizados con las investigaciones de Robert Koch, las realizaciones de Louis Pasteur eran más conocidas ya que la influencia académica francesa era más fuerte. Entre los entusiastas de la bacteriología en Colombia, Lleras Acosta, médico veterinario, era un devoto pasteriano que pertenecía a lo que la historiadora Anne Marie Moulin ha descrito como una orden monástica mundial que tenía su santo fundador, Pasteur, y su regla sagrada, la metodología pasteriana. Pertenecer a la orden era más un asunto espiritual que institucional: los pasterianos debían difundir el evangelio de la nueva revolución científica ${ }^{1}$ (11).

Desde comienzos del siglo veinte, Lleras estuvo involucrado con Pablo García Medina, Juan Bautista Montoya y Flórez, y otros en el movimiento higiénico en Colombia (12). Como veterinario no podía tratar pacientes de lepra, pero como bacteriólogo era conciente del significado potencial de lograr el cultivo del bacilo de Hansen, con la meta última de producir una vacuna. Como veterinario, Lleras estaba condenado a producir vacunas contra el carbón en su laboratorio privado, y a prácticas clínicas rutinarias, ya que éste era uno de los pocos laboratorios de Bogotá. Pero como bacteriólogo, un mundo de posibilidades fascinantes de contactos con la comunidad científica internacional y de gloria nacional se abrían para el entusiasta pasteriano, convencido de que la profilaxis y la terapéutica de la lepra debían ser determinadas por la bacteriología.

En consecuencia, decidió concentrar todos sus esfuerzos investigativos en cultivar el bacilo de Hansen. El cultivo de Mycobacterium leprae presentaba muchas dificultades. Desde 1874, cuando el célebre médico noruego Gerhard A. Hansen había publicado sus primeras observaciones del bacilo y sus teorías acerca del agente causal de la lepra, un sinnúmero de investigadores, comenzando por el mismo

\footnotetext{
1 Para un análisis detallado de la carrera de Federico Lleras Acosta y de su intento de cultivar $M$. leprae, véase (13).
} 
Hansen, había cultivado bacilos ácido-resistentes a partir de nódulos de lepra, pero nadie había podido hacerlos vivir fuera del organismo humano. Estos bacilos eran considerados por algunos como el verdadero $M$. leprae, aunque siempre fracasaron los intentos de replicar el trabajo de aquellos científicos. Otros, por el contrario, afirmaban que se trataba solamente de contaminaciones de laboratorio o de la piel humana puesto que los bacilos ácido-resistentes se encontraban muy extendidos en la naturaleza, donde crecían a partir de productos como la leche o la mantequilla (13).

Debido a la política de segregación obligatoria de leprosos que se practicaba desde 1905, los hospitales no atendian pacientes de lepra. Por tanto, Lleras tuvo que trabajar en el consultorio privado del médico José I. Uribe. En 1933, presentó sus primeros resultados a la Academia de Medicina. En esta primera comunicación, Lleras afirmó haber obtenido un cultivo puro de un bacilo ácido resistente, granuloso, agrupado en globias, con todos los caracteres morfológicos, coloración y manera de agruparse del bacilo de Hansen. Para entonces, no podía ofrecer la prueba de la especificidad del microorganismo cultivado, pues, al no conocerse animal receptivo al bacilo, no se podía llenar el requisito de los tres postulados de Koch: aislamiento, cultivo e inoculación.

Con el fin de buscar una prueba de la especificidad del bacilo en la reacción de desviación del complemento, Lleras preparó un antígeno. La aplicación más conocida de esta técnica es la reacción de Wassermann para el diagnóstico de la sífilis, cuyo agente causal tampoco podía cultivarse. Lleras preparó también un antivirus que, junto con el antígeno, utilizó como tratamiento específico de la lepra. A pesar de la fuerza de sus afirmaciones, Lleras usaba el recurso retórico de la cautela: sabía que necesitaba un mayor número de pacientes para probar su reacción, pero sobre todo, expresaba un sentimiento de marginalidad, característico de científicos que trabajan fuera de los grandes centros: "Ante todo debo declarar que no pretendo haber hecho descubrimientos trascendentales, ni haber revolucionado la Medicina, ni menos haber resuelto el problema de la lepra, ni haber curado ningún leproso. Únicamente (...) vengo a dar cuenta a la
Academia del resultado de mis investigaciones. En cuanto a la originalidad no respondo: he consultado muchas revistas, pero entre nosotros la bibliografía siempre es deficiente, de manera que muchas veces creemos haber hecho un descubrimiento y resulta que es asunto que hace mucho han resuelto en otra parte" (14).

Interesante resulta su afirmación de no "haber curado ningún leproso" y aún así pretender que sus trabajos tuvieran importancia para la campaña antileprosa. Por paradójico que pudiera parecer a algunos, según la nueva orientación que se le estaba imprimiendo a la lucha contra la lepra, la investigación acerca de la etiología, la patología y la terapéutica de la enfermedad debía ser una de las ocupaciones más importantes de los médicos en los dispensarios regionales. De otra parte, discípulos de Lleras ocupaban cargos destacados en los organismos de la higiene pública: Luis Patiño Camargo era director del Departamento Nacional de Higiene, Jorge De Francisco, subdirector, y José Ignacio Chala, jefe de la Sección de Lazaretos; y, por si fuera poco, Lleras había formado parte del Concejo Municipal de Bogotá en 1923, junto con Alfonso López Pumarejo, presidente de la república entre 1934 y 1938. Con aliados tan poderosos, no es de extrañarse que el gobierno creara el Laboratorio Central de Investigación de la Lepra en el dispensario de Cundinamarca y designara a Lleras como su director. Sus planes de investigación serían aprobados por el Departamento Nacional de Higiene y tendría como colaboradores a los médicos de los lazaretos y dispensarios regionales (15). Lleras quedaba convertido así en un flamante investigador de tiempo completo, financiado por el Estado y con cientos de leprosos a su disposición de donde obtener material para sus cultivos.

Su siguiente paso fue buscar la legitimación de sus investigaciones en centros científicos como el Instituto Oswaldo Cruz de Brasil y el Instituto Rockefeller de Nueva York. Para ello, mantuvo contactos permanentes con H.C. Souza Araujo, jefe del Laboratorio de Leprología del Instituto Oswaldo Cruz y miembro del Centro Internacional de Leprología de la Sociedad de las Naciones, quien visitó Colombia en varias ocasiones para 
asesorar la campaña contra la lepra. Souza Araujo fue uno de los científicos que replicó los cultivos de Lleras. En marzo de 1934, Lleras viajó a Nueva York, donde dictó una conferencia sobre la bacteriología del bacilo de la lepra ante la Sociedad Médica Hispano-Americana y visitó el Instituto Rockefeller, algunos de cuyos investigadores intentaron la réplica de sus cultivos, y donde recibió comentarios y sugerencias sobre sus investigaciones (16). Nótese que su conferencia no fue ante el público autorizado del Instituto Rockefeller, sino ante una sociedad profesional de médicos inmigrados, con lo cual quedaba ya claro su papel como científico marginal. A su regreso al país, Lleras inició, con el apoyo del médico Abraham Afanador, sus inoculaciones en ratones y en un mico (Macacus rhesus) obsequiado por el Departamento de Fiebre Amarilla de la Fundación Rockefeller.

En junio de 1936, Lleras presentó nuevos resultados a la Academia de Medicina: durante cuatro años había realizado más de cincuenta réplicas de su cultivo y, según él, el bacilo había conservado durante ese tiempo todos sus caracteres primitivos (17). En esta comunicación, Lleras afirmó haber encontrado la prueba de la especificidad del bacilo, que era al mismo tiempo un nuevo método de diagnóstico temprano de la lepra que llamó 'reacción Lleras' y que podría convertirse en la base de la profilaxis de la lepra. De ser válida esta reacción, la misma definición de la enfermedad se transformaba: el diagnóstico precoz de la lepra implicaba reconocer que había muchos más leprosos de lo que indicaban las estadísticas, ya que el nuevo método permitía declarar leprosa a una persona, aún sin síntomas clínicos. La bacteriología, con métodos que pretendían ser mucho más poderosos que los de la medicina clínica tradicional, prometía establecer la distinción entre salud y enfermedad.

Con el fin de conseguir más aliados que atestiguaran en favor del enunciado de su éxito en el cultivo del bacilo, Lleras solicitó a varios médicos colombianos que realizaran estudios histológicos de órganos y tejidos de animales inoculados con el cultivo Lleras. Juan Pablo Llinás, César Uribe Piedrahita y Manuel Sánchez Herrera declararon las lesiones examinadas como leprosas. Éstas eran pruebas adicionales acerca de la especificidad de su bacilo, así es que según Lleras, lo único que faltaba como prueba definitiva era la inoculación al hombre. Sin embargo, algunos miembros de la Academia de Medicina no estaban convencidos. Para ellos, el cultivo era un vulgar saprófito. Lleras replicaba, con cierto humor negro, proponiendo a los incrédulos dejarse inocular los cultivos con un factor que intensificaba la infección.

En la comunicación de 1936, Lleras anunció la construcción de un moderno instituto de investigaciones en bacteriología, química, serología, anatomía patológica y servicio clínico para experimentación y enseñanza. Allí se formarían los leprólogos que deberían realizar la campaña contra la lepra. También informó que la Dirección Nacional de Higiene respaldada por el poder ejecutivo, daría un vuelco a los sistemas empleados hasta entonces en la lucha contra la lepra y los reemplazaría por una verdadera profilaxis basada en métodos científicos.

Lleras pidió a la Academia nombrar una comisión para verificar sus trabajos puesto que la Dirección Nacional de Higiene, necesitaba conocer el concepto científico para poder implantar oficialmente la reacción de desviación del complemento como medio de diagnóstico y control de los tratamientos (18). El tribunal local de la razón presentó su veredicto en diciembre de 1937. Se trataba de la comisión nombrada por la Academia Nacional de Medicina para estudiar los trabajos de Lleras, formada por Roberto Franco, Julio Aparicio, Alfonso Esguerra y Pedro J. Almánzar. La comisión consideraba que sus conclusiones no eran definitivas puesto que no habia realizado "ensayos de comprobación", sino que se había limitado a realizar un "estudio crítico".

De otra parte, era conciente de las dificultades ya que las investigaciones sobre la bacteriologia de la lepra eran numerosas y la comunidad leprológica no había logrado decidir sobre el valor definitivo de tales trabajos. Como anexo, se incluyó un resumen histórico y cronológico de estas investigaciones. En cuanto al cultivo del bacilo, la comisión consideraba de la mayor importancia que sus cultivos tuviesen caracteres bien definidos y constantes. Sin embargo, como la lepra no se 
transmitía a los animales, no se podía probar su especificidad; todavía era preciso producir las lesiones que Lleras había logrado en inoculaciones en serie para lograr diferenciar el bacilo Lleras de los bacilos ácido-resistentes banales; y los resultados de la reacción de fijación del complemento, ya fuesen alergia o inmunidad, no se podían interpretar todavía. En resumen, la comisión establecía que la parte más importante del trabajo de Lleras era la reacción serológica y consideraba que sus investigaciones deberían continuarse $(19)^{2}$. Aún así, sin una conclusión definitiva, la reacción Lleras comenzó a usarse como método de diagnóstico en los lazaretos y dispensarios colombianos (20).

La situación del cultivo del bacilo de Hansen era verdaderamente confusa en los años treinta. Una lista interminable de investigadores declaraba haber logrado el cultivo de $M$. leprae, al mismo tiempo que proclamaba haber fracasado replicando el trabajo de los demás (21). Evidentemente estamos lejos del cuadro ordenado de método y racionalidad científica, modelo caro a los filósofos, para encontrarnos más bien con la mezcla turbulenta de la ciencia en acción, para usar las palabras del sociólogo Bruno Latour (22). Pero esta confusión no es propia únicamente de este caso particular, sino que caracteriza la práctica de toda ciencia antes que los enunciados se conviertan en hechos científicos.

Un aspecto que se debe resaltar es la ausencia de referencias bibliográficas en los artículos de Lleras. Siete meses después de su primer artículo publicado en la Revista de la Facultad de Medicina de la Universidad Nacional en 1933, Joaquín Grillo, quien se encontraba realizando investigaciones en el Laboratorio de Serología del Instituto de Higiene del Reich en Berlín, publicó en la misma revista un denso estudio sobre el tema (23). Grillo presentó una discusión sobre la seroterapia Carrasquilla, indicando que sus deficiencias se debían a que este investigador no había contado con una biblioteca adecuada y subrayando la

\footnotetext{
${ }^{2}$ No en vano los habitantes de los lazaretos se sabian conejillos de Indias y repudiaban las prácticas de los médicos a las que jamás vieron como acciones que pudieran redundar en su beneficio.
}

importancia que hubiese tenido la conformación de una escuela que hubiese continuado esas experiencias. La segunda parte de su artículo trata de todos los intentos relevantes de cultivar el bacilo de Hansen, incluido el de Lleras. Grillo señalaba que aislar a partir de productos leprosos un bacilo ácido-resistente morfológicamente semejante al bacilo de Hansen era menos difícil que aportar la prueba de su identidad con el agente causal de la lepra y llegaba a las siguientes conclusiones: que los gérmenes aislados por investigadores que declaraban haber logrado el cultivo del bacilo de Hansen pertenecían, en la gran mayoría de los casos, a especies bacterianas diferentes las unas de las otras y que en el estado actual de los conocimientos sobre el tema no era posible establecer de manera definitiva las relaciones que estos gérmenes podían tener con el bacilo de Hansen; para llenar el requisito de la validez, no bastaba una confirmación aislada, era preciso que esos resultados fuesen la regla. Grillo se apoyaba para su discusión en un listado bibliográfico de 160 referencias sobre el tema en español, inglés, francés, alemán e italiano. Lleras sólo conocía parcialmente esta literatura.

Ya era claro que los laboratorios con más recursos, situados no por casualidad en los países más ricos, eran verdaderos 'centros de cálculo', para usar una expresión de Latour, esto es, lugares donde se acumulaba toda la información pertinente, se repetían las experiencias de investigadores dispersos en remotos hospitales y colonias de leprosos en Asia, Africa, Oceanía y Latinoamérica, y se desechaban los intentos fallidos, no sin antes estudiar las razones de sus fracasos. Los laboratorios de algunos países europeos y de los Estados Unidos ya se habían convertido en 'centros de cálculo'. La importancia de estudios como los de Lleras, independientemente de su fracaso o no, radicaba en que en tales centros estas investigaciones se podían repetir, comparar y juzgar a la luz de decenas de intentos semejantes. Los leprólogos del mundo constituian así una red de laboriosos investigadores, pero los éxitos estarían reservados sólo a unos pocos, a aquéllos ubicados en los laboratorios con mayores recursos. 
Por ello, un editorial de 1938 del International Journal of Leprosy, quizás la revista más importante en el tema, convertido en tribunal internacional de la razón, podía lacónicamente señalar que los resultados de Lleras eran "especialmente interesantes" y recomendar que se prosiguieran sus investigaciones (24). El gobierno de López Pumarejo, permanente aliado de Lleras, decidió enviarlo al Congreso Internacional sobre la Lepra que se celebraría en marzo de 1938 en El Cairo, y la Academia Nacional de Medicina, de la cual era presidente, le otorgó el premio al mejor trabajo sobre la lepra. La prensa colombiana trataba a Lleras como héroe. Los titulares del periódico El Tiempo decían: "Leprólogos brasileños piden la asistencia del Dr. Lleras" refiriéndose a una insinuación de Souza Araujo en el sentido de que el Congreso de El Cairo era el lugar indicado para presentar el resultado de sus investigaciones (25). No obstante, Lleras nunca llegó a El Cairo. En un giro casi novelesco, murió el 18 de marzo en Marsella, Francia, en su camino hacia el congreso que debía iniciarse tres días después.

Resulta muy interesante el análisis de lo ocurrido en Bogotá a raíz de la dramática muerte de Lleras. Este falleció de un ataque al corazón, aparentemente ocasionado por la indignación que le produjo la frialdad con que lo habían recibido los investigadores del Instituto Pasteur, frialdad producida por la información que habían recibido de algunos médicos de Bogotá. Los periódicos acusaron a Abraham Afanador y a Joaquín Grillo de haber enviado una carta al leprólogo Emile Marchoux criticando los trabajos de Lleras y afirmando que su envío al congreso de El Cairo obedecía sólo a sus conexiones políticas. Afanador había sido alumno de Marchoux en el Instituto Pasteur entre 1930 y 1933 y había trabajado inicialmente con Lleras. Tanto Afanador como Grillo habían diferido públicamente de las afirmaciones de Lleras. La Federación Médica Colombiana acusó a Afanador de haber faltado a la ética profesional. Afanador se defendió asegurando que sus comunicaciones con Marchoux eran estrictamente científicas y que venían de tiempo atrás, y el asunto eventualmente desapareció del ámbito periodístico que se deshacía en elogios para Lleras. En su honor, el gobierno de Colombia denominó el Laboratorio Central de Investigaciones de la Lepra como "Instituto Federico Lleras Acosta". El congreso de El Cairo en sus conclusiones oficiales deploró la muerte de Lleras, y Luis Patiño Camargo, uno de sus fieles discípulos, fue nombrado su sucesor en la dirección del Instituto (26) ${ }^{3}$. En cambio, los nombres de Afanador y de Grillo, quienes sin duda poseían un significativo potencial científico, prácticamente desaparecieron de la escena científica colombiana, condenados por haber osado criticar a un intocable, aunque los hechos posteriores les dieran la razón.

El breve informe de la comisión oficial de este congreso sobre el cultivo in vitro de $M$. leprae, otro tribunal de la razón, señalaba que se había realizado mucha investigación en este sentido, pero que los resultados de unos investigadores jamás habían logrado ser repetidos por otros, de donde se deducía que los problemas del cultivo del bacilo de Hansen no se habían resuelto satisfactoriamente y se alentaba a los científicos a continuar este tipo de trabajos (27). A partir de entonces, se multiplicaron las voces disidentes en relación con las afirmaciones de Lleras. En el Brasil, P.C.R. Pereira encontró enormes discrepancias entre sus observaciones y las del científico colombiano (28). En los Estados Unidos, S.H. Black y H. Ross concluyeron que la reacción Lleras carecía de valor práctico para el diagnóstico de la lepra (29). Así, la comunidad leprológica internacional, como último tribunal de la razón, convirtió las investigaciones de Lleras en uno más entre los muchos intentos fallidos de cultivar $M$. leprae, tal como lo habían juzgado Afanador y Grillo.

El que Lleras se hubiese apoyado en el poder político para lograr las condiciones necesarias para adelantar sus investigaciones es normal: esto es lo que todo científico ha hecho y debe hacer para tener éxito. El problema radicó más bien en la escasa institucionalización de la actividad científica que se tradujo en la inexistencia de la

\footnotetext{
${ }^{3}$ Miemuro del comité, estuvo en desacuerdo con el informe oficial y añadió a éste una afirmación según la cual el cultivo del bacilo de Hansen había sido logrado por el patólogo y bacteriólogo soviético W. Kedrowsky y por algunos otros investigadores, sin mencionar sus nombres.
} 
crítica por pares y en una actitud complaciente por parte de la prensa. Con todo, las tentativas de Carrasquilla, de Lleras y de otros contribuyeron a crear una tradición de investigación experimental prácticamente inexistente hasta entonces en Colombia; tradición de investigación que, en muchos casos, quedaría signada por el síndrome de la espectacularidad y de la costumbre de informar primero a la prensa acerca de los supuestos hallazgos, que a los propios pares. No hay duda de que discípulos de Lleras y otros investigadores prosiguieron y expandieron estos estudios después de su muerte. En 1940, el Instituto Lleras poseía modernas instalaciones con laboratorios de serología, química biológica, microbiología, anatomía y patología, oficinas médicas, salón de conferencias, biblioteca, museo de anatomía y patología, pabellón para pacientes y un área para animales de experimentación. Los programas de investigación, en manos de un equipo de cinco investigadores de tiempo completo, daban especial importancia al estudio de la transmisión de la enfermedad, ya que el nuevo cuerpo de leprólogos estaba convencido de que, sin la comprensión de este proceso, la profilaxis de la lepra era sólo empírica (30).

En cuanto a la lucha contra la lepra, el resultado fue menos afortunado: las autoridades higiénicas asumieron una actitud cientificista confiando excesivamente en la posibilidad de la producción de una vacuna para controlar la expansión de la enfermedad, antes que en promover reformas sanitarias, sociales y políticas para erradicar la pobreza y la desnutrición, caldo de cultivo indudable de la lepra. Ei ejemplo de Noruega había mostrado que era posible detener la expansión de la infección a través de la mejora de las condiciones de vida de la población y a través de un cuidadoso aislamiento en hospitales donde se investigaba intensamente la enfermedad. Pero en Colombia se impuso una visión que prefirió confiar en una promesa tecnocrática antes que en la democracia.

\section{Referencias}

1 Obregón D. Lepra, exageración y autoridad médica. Asclepio 1998;L-2:131-53.

2. Obregón D. The social construction of leprosy in Colombia, 1884-1939. Science, Technology and Society 1:1-23.
3. Carrasquilla JD. Disertación sobre la etiología y el contagio de la lepra. Revista Médica 1889;13:441-84.

4. Danielssen DC, Boeck CW. Traité de la Spedalsked ou Eléphantiasis des Grecs. Monograph. Paris: J.B. Ballière, 1848.

Danielssen DC, Boeck CW. Atlas de la Lèpre. Bergen en Norvèege, 1847. Édition commemorative du centenaire. Rio de Janeiro; 1946.

5. Moulin AM. Le dernier langage de la médecine: histoire de l'immunologie de Pasteur au Sida. Paris: Presses Universitaires de France; 1991. p.68-9,143.

6. Carrasquilla JD. Memoria sobre la lepra griega en Colombia. En: Mittheilungen und Verhandlungen der internationalen wissenschaftlichen Lepra-Conferenz zu Berlin im October 1897, vol.1. Berlin: Verlag von August Hirschwald; 1897. p.81-124.

7. Rico E, Carrasquilla JD. Repertorio de Medicina y Cirugía 1925;16-7(187):304-13.

8. Carrasquilla JD. Memoria sobre la Lepra Griega en Colombia.122-4.

9. Carrasquilla JD. La lepra: etiología, historia y profilaxis, Memoria presentada al Tercer Congreso Científico Latinoamericano, Rio Janeiro, agosto de 1905. Revista Médica 1905;25:289-302.

10. Carrasquilia JD. Los sanatorios y la lepra, En: Revista Médica, 1905,26:65-71.

11. Moulin AM. Patriarchal science: the network of the overseas Pasteur institutes, science and empires: historical studies about scientific development and European expansion. Petitjean P, Jami C, Moulin AM, editors. Dordrecht: Kluwer Academic Press; 1992. p. 307-22.

12. Obregón, D. De la veterinaria a la bacteriología: Federico Lleras Acosta o la lucha por la construcción de una carrera científica en Colombia. En: Arboleda LC, Osorio $C$, editores. Nacionalismo e internacionalismo en la historia de las ciencias y la tecnología en América Latina. Cali: Universidad del Valle. p. 229-55.

13. Loewenstein E. Bacteriological diagnosis of leprosy by means of blood culture. Int J Leprosy 1933;1:39-44.

14. Lleras F. Algunas consideraciones sobre la biología del bacilo de Hansen. Comunicación hecha a la Academia de Medicina el día 30 de mayo de 1933. Revista de la Facultad de Medicina 1933;1:929-35.

15. Decreto Número 1649 de 1934. Revista de Higiene (segunda época) 1934;15:362-3.

16. Noticias médicas. Conferencia sobre lepra en Nueva York. Revista de la Facultad de Medicina 1934;2:733.

17. Lleras F. Pruebas de la especificidad de un bacilo aislado de la sangre de los leprosos. Comunicación hecha a la Academia Nacional de Medicina el día 16 de junio de 1936. Bogotá: Imprenta del Departamento; 1936. p. 3-7.

18. Ibid., p.179-80. 
19. Franco R, et al. Los trabajos del Profesor Federico Lleras Acosta sobre lepra. Revista de la Facultad de Medicina 1938;6:569-84.

20. León-Gómez A. La ciudad del dolor. Bogotá: Sur América; 1927. p. p.194-205.

21. McKinley EB, Verder, E. Cultivation of Mycobacterium Jeprae. Int J Lepr 1933;1:351-3.

22. Latour B. Science in action. How to follow scientists and engineers through society. Cambridge, MA: Harvard University Press; 1987. p.15.

23. Grillo J. Al margen de la seroterapia antileprosa y del cultivo del bacilo de Hansen. Revista de la Facultad de Medicina 1933;2:387-419.

24. The immunology problem. Int J Lepr 1938; 6:98.
25. El Tiempo. Nov. 24,1937:1.

26. Congreso Internacional de Lepra. Conclusiones fundamentales. Revista de Higiene 1938;XIX:8.

27. Reenstierna J. Reports on meetings. Int J Lepr 1938;6:408-9.

28. Pereira PCR. Current literature: a reaçao de Lleras Acosta na leprose. Int J Lepr 1939;7:123.

29. Black SH, Ross $\mathbf{H}$. The complement fixation reaction of Lleras in leprosy. Int J Lepr 1941;9:270.

30. Patiño L. Instituto de Investigación Federico Lleras: objeto de este centro de investigación, organización técnica y estudios que se adelantan. Revista Colombiana de Leprología 1940;1:261-6. 